\title{
Coating strategies using layer-by-layer for cell encapsulation
}

Mariana B. Oliveira, ${ }^{[a]}$ Javad Hatami, ${ }^{[a]}$ and João F. Mano*[a]

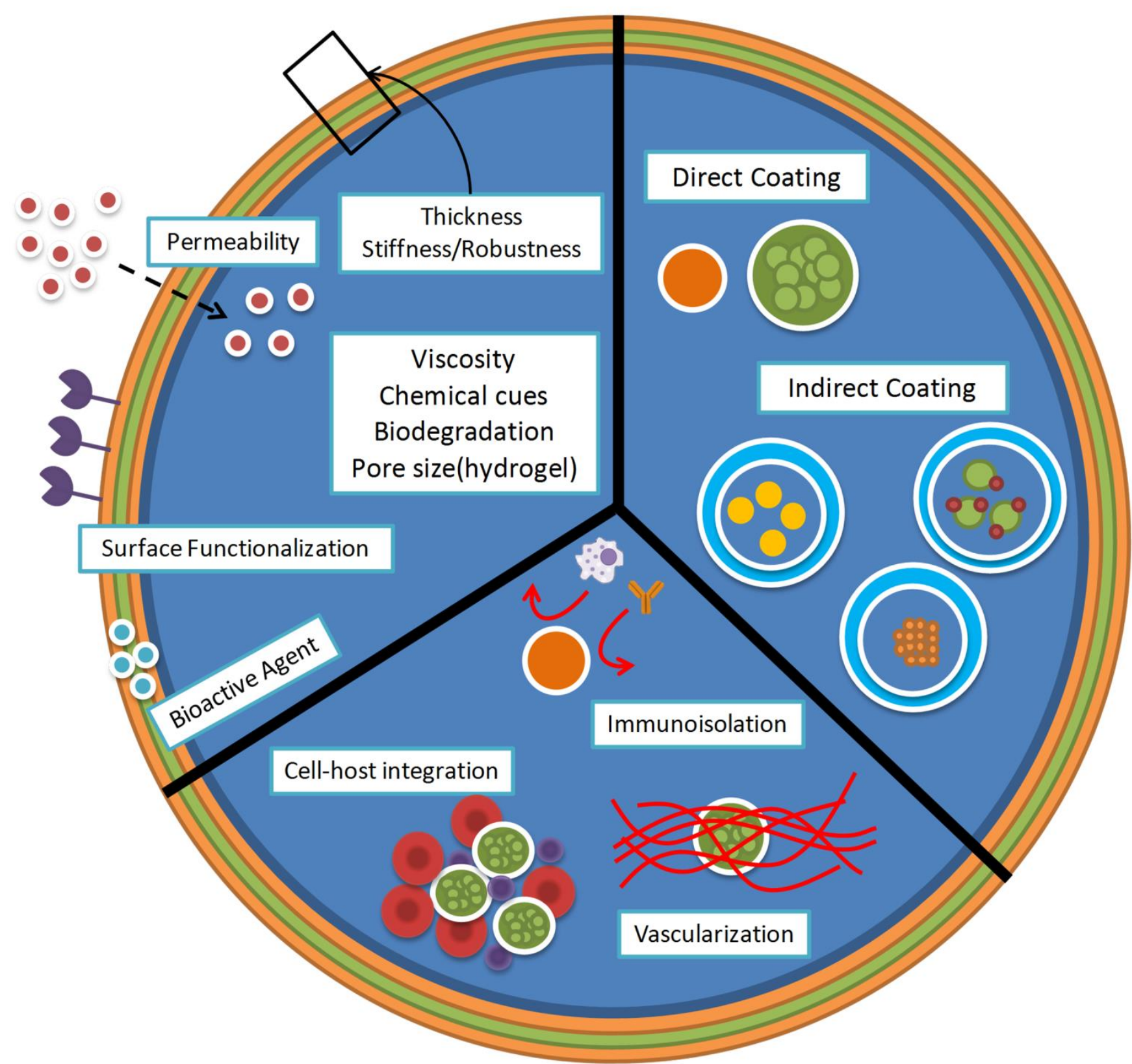

For internal use, please do not delete. Submitted_Manuscript 
Abstract: The layer-by-layer ( $L b L)$ deposition technique is widely used to develop multilayered films based on the directed assembly of complementary materials. In the last decade, thin multilayers prepared by LbL deposition have seen application in biological fields, namely for cellular encapsulation, due to their versatile processing and tunable properties. Their use was suggested as an alternative approach to overcome the drawbacks of bulk hydrogels, for endocrine cells transplantation or tissue engineering approaches, as effective cytoprotective agents, or as a way to control cell division. Nanostructured multilayered materials are currently used in the nanomodification of single cells and cell aggregate surfaces, and are also suitable as coatings for cell-laden hydrogels or other biomaterials, which may later be transformed in highly permeable hollow capsules. In this Focus Review, we discuss the applications of LbL cell encapsulation in distinct fields, including cell therapy, regenerative medicine and biotechnological applications. Insights regarding practical aspects required to employ $\mathrm{LbL}$ for cell encapsulation are also provided.

\section{Introduction}

Nano-engineered materials have seen great development in the last decades. A particular branch of this field is related with materials built with bottom-up molecular or supramolecular assembly techniques, which allow a fine control over materials' composition, structure and function, in a much more precise way than bulk materials ${ }^{[1]}$. Such enhanced structural precision represents an added-value for fields as design of functional (bio)materials, biomedical engineering and biotechnology ${ }^{[2]}$.

In this Focus Review, the directed molecular assembly technique - layer-by-layer (LbL) deposition - will be discussed as a tool for cell encapsulation. LbL deposition gained recognition in several research and industry fields after the report of polyelectrolyte multilayers by Decher and Hong in $1991^{[3]}$. The concept behind the LbL technique is the sequential adsorption of complementary molecules on a surface. This step-by-step approach allows the deposition of multilayered films with tailored heights and composition. Although layer deposition often occurs via electrostatic interactions between complementary molecules, non-electrostatic mechanisms have also been suggested ${ }^{[4]}$. The LbL method avoids molecular complexation phenomena due to the intercalating washing steps during material deposition. Such steps, besides avoiding the contamination of the following adsorbing solutions, also allow the stabilization of the nanometric individual layers and permit the construction of films with fine and highly controlled compositions ${ }^{[4 a]}$. LbL multilayer buildup may be

[a] MB Oliveira, PhD, J Hatami, PhD and Prof. JF Mano, PhD Department of Chemistry, CICECO - Aveiro Institute of Materials University of Aveiro

3810-193 Aveiro, Portugal

Corresponding author: Prof. João F. Mano

Address: Department of Chemistry, CICECO - Aveiro Institute of Materials. University of Aveiro. 3810-193 Aveiro, Portugal. Tel: +351 234370733. E-mail: jmano@ua.pt achieved through a variety of deposition methods including dipcoating, spin-coating, spraying and perfusion, which have been already extensively reviewed ${ }^{[5]}$. Deposition methods may be selected according to the process-depended parameters such as availability of material (e.g. spin-coating and spraying techniques minimize amounts of necessary material and increase the process speed and automation), and compatibility of the method with the coating of complex shapes ${ }^{[5]}$.

A plethora of materials may be used as assembly blocks in LbL, including polymers, peptides, carbon nanotubes, clays, dyes, metal oxides, nucleic acids, enzymes and viruses. The possibility of preparing multilayered films by the LbL method with non-toxic materials ${ }^{[5-6]}$ makes this technique suitable for application in the biotechnology and biomedical devices development fields. A complete Review about the applications of LbL technology in these areas can be found in Ref.[6]. As added assets to its versatility, the LbL technique can be performed in substrates with several chemistries, sizes (from nano-sized structures to millisized ones) and shapes. Although LbL coatings are most often constructed in planar surfaces, they can also be performed in porous substrates, colloidal particles, spheres and cylindrical structures with fine control over thickness, stiffness, chemical composition and swelling of multilayers ${ }^{[7]}$. The nanoscale tailoring of these properties may be achieved through the modulation of the adsorbed materials' properties, such as charge density, composition or molecular weight. Aspects as solvent quality or presence of ions and environmental conditions, including deposition temperature, also interfere with the final properties of the multilayers ${ }^{[4 a]}$.

The ability to perform LbL coatings at physiological conditions, including $\mathrm{pH}$, temperature and ionic strength, elicited its envisioning for cell encapsulation. Since the first report on cell encapsulation using alginate bulk hydrogel beads ${ }^{[8]}$, a great number of works have sought the optimization of materials and processes used in this field. Cell encapsulation aims at entrapping viable and functional cells within a semi-permeable biocompatible matrix. Therefore, such matrix must be built from cytocompatible materials permeable to oxygen, nutrients, and cell metabolites byproducts. Other matrix properties are highly dependent on specific applications, which include immunoprotection of allo/xeno-transplanted cells, support for tissue engineered constructs, preparation of fermentation products in the biotechnological industry, or cytoprotection of animal cells, bacteria and yeasts.

Hydrogels - highly hydrated polymeric materials crosslinked to form three-dimensional networks - were considered for a long time the gold-standard of cellular encapsulation ${ }^{[9]}$. However, low permeability and instability problems associated with the use of bulk hydrogels raised the need for alternative systems based on the coating of biological structures with LbL method or even stand-alone LbL hollow capsules. The processing characteristics and material properties/application relationship of hydrogels have been widely discussed (complete Reviews on Refs. ${ }^{[10]}$ ). Due to the aforementioned limitations, hydrogels in the form of microparticles are often used in implantation scenarios, as their small size allows the efficient perfusion of gases and nutrients/waste in the whole biomaterial structure. Two of the

For internal use, please do not delete. Submitted_Manuscript 
most important techniques employed in the cell microencapsulation field using hydrogels are bioelectrospraying and cell electrospinning. Those consist in extruding/spraying a polymer solution pumped through a needle connected to a highvoltage generator ${ }^{[11]}$. A method to prepare compartmentalized multilayered electrosprayed hydrogel microparticles was suggested $^{[12]}$. The wide potential of cell-laden electrosprayed and electrospun structures can be iterated from several works where they are applied in vivo as models to study the biocompatibility of biopolymers with encapsulated cells and their behavior after implantation ${ }^{[13]}$. These structures were also used as in vitro 3D disease models. As an example, a monocyte immortalized cell line was encapsulated using bio-electrospraying technique in different combinations of alginates and collagen. The result of this study proves no cytotoxic effcet of bio-electrospraying on cell viability nor prolifertaion of cells ${ }^{[14]}$. In another application, the use of Mycobacterium tuberculosis-infected cells encapsulated in a collagen matrix by bioelectrospraying allowed concluding that collagen destruction is an important event in tuberculosis bacterial transmission ${ }^{[15]}$. The use of bioelectrosprayed and cell electrospun structures as cell-laden hydrogels for the further preparation of LbL-coated structures is a promising route to prepare such biomaterials in a high-throughput and rapid manner. Cell encapsulation using the LbL deposition technique can be sorted in two categories: direct and indirect cell coating (represented schematically in Figure 1). The direct coating technique involves the deposition of the multilayer film on the surface of single cells or cell aggregates. The indirect method refers to the encapsulation of cells inside a hydrogel or a cytocompatible biomaterial, which is later coated with a LbL film. The hydrogels may have two roles: they may be used as such in the final application (i.e., a coated bulk biomaterial), or serve as a sacrificial template to further produce hollow shell-core systems, obtained by core liquefaction after the LbL deposition of the multilayer coating. In the next section, we discuss the applications of the LbL technique for both types of cell encapsulation (some representative examples in Table 1). Relationships between materials and LbL deposition conditions urge to be systematically allocated to suitable applications and final properties of the encapsulating multilayers. A schematic representation referring to the multilayer and core properties of LbL-based coating systems can be found in Figure 2.

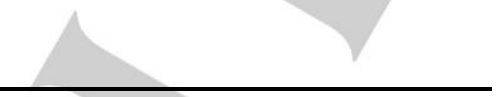

Mariana B. Oliveira has a background in Biomedical Engineering from the University of Minho (Portugal) and a PhD in Biomedical Engineering from the same institution. She specialized in the development of highthroughput strategies for biomaterials design. Currently, she is a postdoctoral researcher at the University of Aveiro. Her current research interests are pancreatic islets transplantation, stem cell/biomaterials interactions and highthroughput screening.

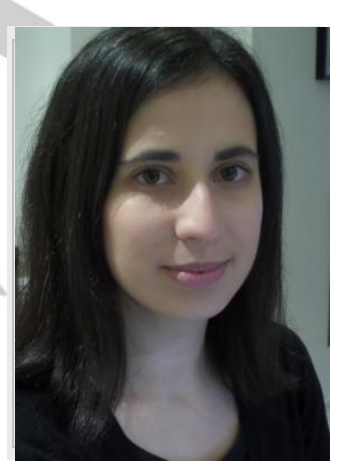

Javad Hatami obtained his $\mathrm{PhD}$ in Bioengineering in 2015 at University of Lisbon-IST (Portugal) within the framework of MIT-Portugal program. He is currently a postdoctoral fellow at the University of Aveiro. As a member of ELASTISLET project, a European project to create immune-isolated and biomimetic scaffolds for pancreatic cell transplantation, he is interested to combine leading technologies with biomaterial design and cell therapy to treat diabetes mellitus.

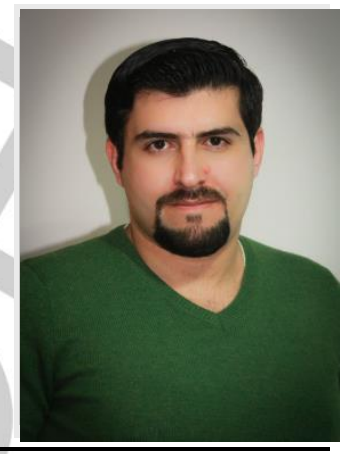

João F. Mano is a Professor at the Chemistry Department of University of Aveiro. His current research interests include the use of biomaterials and cells towards the development of transdisciplinary concepts for biomedical applications, especially aimed at being used in tissue engineering and in the controlled delivery of bioactive molecules. In particular, he and his group have been developing materials, mainly derived from biodegradable polymers, with stimuliresponsive or bio-instructive behaviour, or

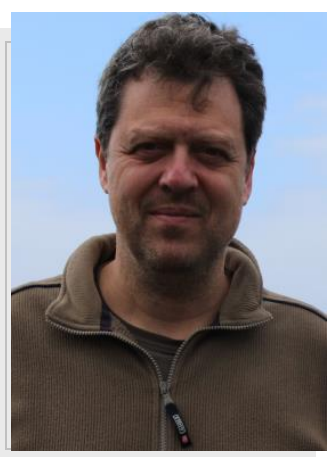
biomimetic and nano/micro-technology approaches applied to biomaterials and surfaces.

\section{Layer-by-layer for cell encapsulation}

\subsection{Direct coating}

The LbL deposition of polyelectrolytes or other complementary materials is an appropriate strategy for single cell encapsulation, often taking advantage of the negative charge of the cell surface. Moreover, it is amenable to be performed under mild conditions and is compatible with nanoscale precision, modifiable surface characteristics and tunability ${ }^{[16]}$. Composition ${ }^{[17]}$, charge ${ }^{[18]}$, mechanical properties ${ }^{[19]}$ and morphology ${ }^{[17]}$ of $L b L$ coatings strongly affect cell surface and function. Generally, a polycationic element is deposited as the first layer, considering the negative charge of cell membrane, then sequential deposition of negativepositive components are arranged until the desired thickness and properties are reached. Besides electrostatic assembly of materials, other cell-materials interactions, such as cell surface integrins-extracellular matrix proteins domains (e.g. RGD), were suggested to directly coat cells. For example, LbL constructs were built based on specific interactions between such proteins (e.g. fibronectin and gelatin) ${ }^{[20]}$.

\subsubsection{Single cell coating}

One of the early works on cell surface LbL coating reported the electrostatic LbL coating of bovine platelets with cationic poly(dimethyldiallylammonium chloride) (PDADMAC) and anionic

For internal use, please do not delete. Submitted_Manuscript 
sodium poly(styrenesulfonate) (PSS) ${ }^{[21]}$. Inhibition of platelet aggregation and control of platelet secretion, by controlling the thickness and compositions of the LbL film, showed the possibility of manipulating single cell function using LbL coatings. Since then, different cells were coated by the LbL strategy, including yeasts $^{[22]}$ (Figure 3A), stationary-phase bacteria ${ }^{[23]}$, wild type strain yeast ${ }^{[24]}$, dormant bacterial spores ${ }^{[25]}$, stem cells ${ }^{[26]}$, red blood cells ${ }^{[27]}$, fibroblasts ${ }^{[17]}$ and endothelial cells ${ }^{[28]}$. Fakhrullin and co-workers reviewed the direct coating of single cells using LbL methodologies for several applications, including the use of cells as sacrificial templates to produce microcapsules, LbL assembly of cells and cell surface modification with nanoparticles ${ }^{[29]}$. Historically, single cell encapsulation with LbL assembly saw its initial progress with microbial cells due to their simple structure, broad availability and biotechnological application [22]. Later on, animal cells were also encapsulated using LbL coatings. Unlike the thick and resilient lipid bilayer of microbial cells, animal cells lack polysaccharide-reinforced cell wall which makes them very fragile and prone to osmotic pressure and mechanical stresses. Therefore, a more careful choice of materials for animal cell coating is required ${ }^{[30]}$. LbL encapsulated animal cells were used in the field of biosensors ${ }^{[31]}$, drug delivery and regenerative medicine ${ }^{[30]}$. Regarding cell transplantation strategies, single cell encapsulation of erythrocytes with a bilayer of alginate and chitosan-graft-phosphorylcholine surrounded by two bilayers of alginate and poly-l-lysine-graft-polyethylene glycol was performed to surpass the binding of antibodies and therefore to avoid immunorejection of these cells ${ }^{[27]}$.

Early works on microbial cells showed the ability of LbL technique to maintain cell viability, and controlling cell proliferation and division ${ }^{[32]}$. More recently, bacteria with their surfaces modified with magnetic iron oxide or silver nanoparticles were used as "nanobaits" for microworms (Caenorhabditis elegans). Surfacemodified microorganisms were provided to the nematodes as their sole food source as a way to label them magnetically and test the toxicity of such nanomaterials in vivo[33]. LbL coatings were used as cytoprotective shells and as a way to functionalize cell surface by adjusting physiochemical properties of the coating such as thickness, components and charge of multilayers ${ }^{[32]}$. For example, mouse mesenchymal stem cells (MSCs) were encapsulated in poly(L-lysine) and hyaluronic acid LbL films (Figure 3B); the flexible and viscoelastic polyelectrolyte layer was compatible with cellular viability, maintenance of MSCs morphology up to one week, and prevented cellular proliferation ${ }^{[26 a]}$. Control over yeasts division using nanometric coatings of catechol-grafted polyethyleneimine and hyaluronic acid was suggested by varying the number of $\mathrm{LbL}$ nanolayers ${ }^{[34]}$. The prevention of cell division could also be controlled temporarily by the degradation of the nanocoatings ${ }^{[35]}$. To the best of our knowledge, a remaining challenge regarding the coating of dividing cells is the development of highly flexible shells that allow nanocoatings to persist around cells after division, coating them effectively and entirely.

Multilayer coating of single cells could be used to create defined microenvironments to control cell proliferation and differentiation by, for example, the incorporation of growth factors in the multilayers. It was recently demonstrated that insulin-like growth factor-1 loaded into the cell capsule could be released into the medium in a time- and $\mathrm{pH}$-dependent manner, thus enhancing proliferation of neural stem cells (NSCs) ${ }^{[26 b]}$. Though microscopy results demonstrated that $\mathrm{LbL}$ encapsulated NSCs were in a spherical shape and that their cytoskeletal structure was restrained, the gelatin/alginate polyelectrolytes used for LbL cell coating were cytocompatible and did not significantly affect the viability of NSCs. LbL coating of single human T-cell line (Jurkat cells) demonstrated an effective cell shelling with no adverse effects on viability, morphology and cell functionality ${ }^{[36]}$.

The LbL technique was used to deposit bioinspired mineralized organic/inorganic multilayers for the cytoprotection of coated single cells from physical, chemical, and environmental elements ${ }^{[37]}$., The use of different polyelectrolyte pairs (e.g. PDADMAC/poly(acrylic acid) (PAA), poly(allylamine hydrochloride) (PAH)/PAA, PAH/PSS) to support the deposition of mineral matrixes on yeast ( $S$. cerevisiae) membranes showed that mineralization efficiency is dependent on cells' interfacial energy, differing with the deposition of different coatings ${ }^{[38]}$. An extracellular matrix $\mathrm{LbL}$ nanocoating was shown to be effective on protecting hepatocyte carcinoma (HepG2) cells from extreme physical stress during centrifugation ${ }^{[39]}$. LbL deposition of multilayers is also used to coat transplanted allogenic cells, to avoid immune rejection, in applications as endocrine cell transplantation or regenerative medicine. Human cartilage cells encapsulated in LbL films of sodium cellulose sulfate (polyanion) and polydiallyldimethylammoniumchloride (polycation) were effectively immunoprotected in vivo ${ }^{[40]}$. The ability to tune the physiochemical properties of $\mathrm{LbL}$ assembly provides an interesting avenue to perform biophysical studies on single cells. For example, cell division forces and cell protection from shear stress were studied by tuning the mechanical properties of LbL nanocoatings ${ }^{[41]}$.

In a new concept called "cell-accumulation technique", a bottomup approach was used to fabricate a thick vascularized tissue by encapsulation of different cells with LbL coating of fibronectingelatin multilayers ${ }^{[28,42]}$ (Figure $3 \mathrm{C}$ ). In this technique, single layers of LbL-coated endothelial cells were cultured in precise positions between 4 layers of LbL encapsulated human dermal fibroblast cells in vitro in order to obtain 3D vascularized tissues ${ }^{[28]}$ or human skin equivalent containing vascular network ${ }^{[42]}$. Celloidosomes are an innovative concept suggested as complex assembled structures of living cells using LbL approaches and colloidal interactions, with potential application as biologica microcontainers or tissue engineering of hollow transplants ${ }^{[43]}$. Yeasts treated with PAH were assembled around oxygen bubbles (obtained by vortexing), and later coated with polycationic carboxymethyl cellulose, leading to circular structures constituted by a single layer of yeasts. In another approach, yeasts treated with a PAH/PSS/PAH were assembled around calcium carbonate crystals, crystallized in conditions leading to different shapes (spherical, needle-like and cubical). The crystals were then sacrificed using ethylene diamine tetraacetic acid (EDTA), and celloidosomes with different shapes remained stable. 
The exposure of the cell surface to a cationic layer, as the result of the electrostatic LbL coating, may cause cell membrane disruption, leading to apoptosis. Due to minimal exposure of cells to the toxic polycations and higher cell capsule permeability, LbL coating based on hydrogen bonding resulted in significant higher cell viability $(79 \%)$ compared to the use of a ionically paired coating $(20 \%)^{[44]}$. For long term preservation of cells, those with less proliferative capacity are usually considered suitable for LbL encapsulation due to the limitation of space inside the capsule.
In the 1990s, a first clinical study found that islets from cadaveric donors encapsulated in alginate hydrogels were able to reduce the required dose of both immunosuppressants and exogenous insulin in a diabetic patient ${ }^{[4]}$. Because mature islet cells do not readily divide, cell aggregate encapsulation of pancreatic cells for allo-transplantation is an interesting strategy. However, initial systems based on the use of bulk hydrogels showed problems such as limitation on the transplantation site due to the large volume of the implant, hypoxic death of cells, poor diffusion of

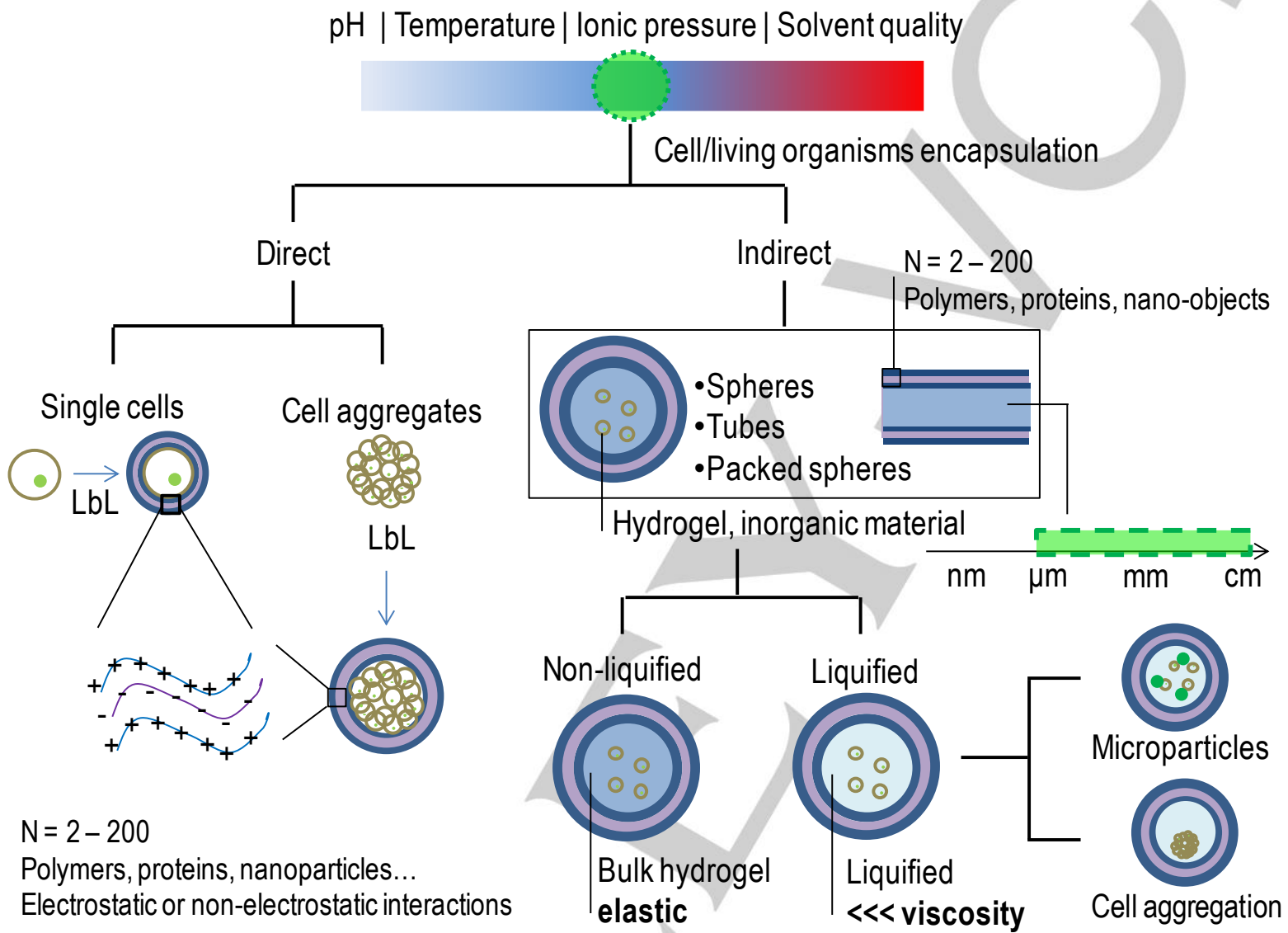

Despite the advantages of LbL technique for cell encapsulation, direct cell coating with LbL may result in nanometer-particle uptake which may compromise cell viability ${ }^{[45]}$.

An automated and centrifugation-free process for the LbL coating of live cells was achieved by modifying yeasts cells with magnetic

oxygen and nutrients into the central cell mass, as well as incomplete immune protection and inadequate biocompatibility of the encapsulating materials ${ }^{[16 b]}$. The LbL technique was employed in an attempt to avoid common problems associated with the traditional pancreatic islet's encapsulation techniques ${ }^{[48]}$.

Figure 1. Schematic representation of the different structures that can be obtained with LbL cellular encapsulation. The LbL deposition technique allows building cell encapsulation coatings under physiological conditions (e.g. temperature, $\mathrm{pH}$, ionic strength). LbL coatings are achieved, most commonly, by electrostatic interactions between molecules; however, they may also be obtained by non-electrostatic phenomena such as hydrogen bonding. A wide range of materials may be used to produce such coatings, and their properties are amenable to be adjusted by altering the number of cycles of deposition. The figure addresses "direct coating" of both single cells and cellular aggregates, as well as "indirect coating" of hydrogel or inorganic templates. Such sacrificial templates (in the size range of few micrometers to several millimetres) may be used as cell culture substrates or as leachable materials that allow the incorporation of soluble (e.g. growth factors) or solid substrates for cell adhesion (e.g. microparticles) inside the liquefied immunoprotected capsule.

nanoparticles ("cyborg cells"), and by subsequently treating them in a microfluidic device that allowed the alternate passage of polyelectrolyte and washing solutions ${ }^{[46]}$.

\subsubsection{Cell aggregates coating}

For internal use, please do not delete. Submitted_Manuscript
Aqueous techniques attempted to be used during LbL coating such as centrifugation, selective withdrawal and microfluidics were not suitable for islet cell encapsulation ${ }^{[49]}$. Therefore, an automated filtration process developed for LbL nanothin-coating on mice islet cells provided less user variability, increased efficiency, and eliminated laborious processing tasks ${ }^{[49]}$. In an 
attempt to microencapsulate hamster's islet cells, poly(ethylene glycol)-conjugated phospholipids was used as a base polymer with sequential layers of sodium alginate and poly(I-lysine) deposited in vitro, resulting in a cytocompatibile system ${ }^{[50]}$. In one elegant study, to control the size of transplant volume, the LbL self-assembly of poly(l-lysine)-g-poly(ethylene glycol)(biotin) and streptavidin was applied to the aggregate of murine islet cells and the in vivo allograft of the encapsulated islets showed no sign of toxicity ${ }^{[48]}$. Several attempts of LbL coatings were performed to study the coating biocompatibility, survival, viability and enhanced insulin secretion of islet cells using animal models ${ }^{[30,48,50-51]}$.

\subsection{Indirect coating}

Indirect LbL coating for cellular encapsulation may give rise to two different types of functional structures (Figure 1): (i) bulk biomaterials (e.g. hydrogels) with modified surfaces or (ii) hollow capsules. In case (i), cells remain in contact with the bulk biomaterial used for its initial encapsulation, which is usually a hydrogel. The LbL coating performed on the outer part of the bulk material may have several functions: the stabilization of the hydrogel, a more fine control of the diffusion and/or release of molecules into and from the material, or the enhancement of the integration of the materials in implantation sites. However, the use of hydrogels for cell encapsulation often elicits problems of permeability, leading to cellular stress due to the imposition of the capsule size to cells. This has been reported for pancreatic islets, where core hypoxia and delayed insulin secretion have been observed while using alginate hydrogels ${ }^{[52]}$. Such limitations may be overcome by the design of materials described in the case (ii), where the core hydrogel used to encapsulate cells is liquefied after LbL deposition (Figure 3D). The hydrogels serve as an initial sacrificial template for the construction of hollow capsules, whose permeability is solely determined by the characteristics of the LbL coating.

\subsubsection{LbL-coated bulk hydrogels}

Despite the wide range of applications of nanocoated hydrogels, examples have been limited to cell-free control of perfusionbased, drug delivery from hydrogels ${ }^{[53]}$ and functionalization of the outer part of hydrogels to promote cellular adhesion ${ }^{[54]}$ or bacterial antifouling properties ${ }^{[5]}$. Regarding cell encapsulation, this approach was used for pancreatic islets encapsulation for cell transplantation, where it has been used to control materials swelling and degradation ${ }^{[56]}$. Moreover, the coating of alginate hydrogels allowed a tight control and prevention of the release of microbial cells, avoiding the undesired exposure of the microorganisms to the outside environment ${ }^{[57]}$. Future implementation of multilayer nano-modified hydrogels may comprises the control of immune response upon implantation, recruitment of bioactive factors and control of physicochemical/rheological properties of the hydrogels, including stickiness or lubrication.
After the modification of hydrogels' surfaces with nanostructured multilayers, the hydrogel may be liquefied generating a hollow capsule ${ }^{[58]}$. This approach may be particularly useful in applications requiring high permeability of molecules (e.g. oxygen), in order to avoid core cell death due to hypoxia, lack of nutrients or accumulation of toxic metabolites. These structures require a careful design, which must take into consideration the biomaterial's final application, since capsules are more prone to disruption than the LbL-coated structures comprising the initial hydrogel. Hollow LbL capsules may be modulated to withstand high hydrostatic pressure and compression - in the case of biomaterials targeting implantation -, and shear stress, - mainly for biotechnological approaches including the use of bioreactors. LbL-coated hollow capsules have been used as cell-free biomaterials, targeting post-processing cell seeding for tissue regeneration approaches. For these applications, calcium carbonate and paraffin were formed in a variety of shapes including single spheres, packed spheres and tubes ${ }^{[76,59]}$. These structures acted as substrates for LbL coating of natural origin polyssacharies (e.g. chitosan and alginate) and recombinant peptides (e.g. elastin-like recombinamers), giving rise to structures as porous scaffolds for tissue regeneration [58a], hierarchical micro-nano structures prepared by sequential LbL steps ${ }^{[60]}$ and tubes for vascular substitution ${ }^{[7 b]}$.

LbL multilayer coatings were also performed in cell-containing alginate and calcium carbonate templates. For microbiological applications, calcium carbonate microspheres were used to encapsulate E. coli, and the presence of the multilayers allowed an increase in the lag phase of the bacteria ${ }^{[61]}$. Animal cells have also been targeted in such approaches. A fibroblast cell line was encapsulated in alginate millimetric spheres, which were then LbL coated with alginate and chitosan multilayers ${ }^{[58 b]}$. After the liquification of the alginate core, the cells remained in the hollow capsule in the liquefied environment, showing high viability rates. Similar strategies were extended to other template shapes, including tubular structures ${ }^{[7 a]}$. One of the problems associated with the encapsulation of adherent cells in hollow capsules with a liquefied environment is the incompatibility of their long-term culture in suspension conditions. Upon the formation of an avascularized microtissue in the liquefied environment inside the capsules, in the long term, such cell mass will develop a hypoxic necrotic core. In order to solve this problem, fibroblast cells (L929 cells) were encapsulated in a chitosan/alginate multilayer hollow capsule incorporating poly(L-lactic acid) microparticles as cell adhesion sites ${ }^{[58 a]}$. This proof-of-concept work reported for the first time a hollow LbL structure able to support adhesion and proliferation of anchorage-dependent cells on the core of the capsule ${ }^{[58 a]}$, while maintaining high permeability and immunoprotective features. Although not done yet, this approach may also bring a new insight for cellular aggregates encapsulation, namely for pancreatic islets, as it may allow tailoring the liquefied medium surrounding the islets with pancreas native proteins.

\subsubsection{LbL hollow capsules}

For internal use, please do not delete. Submitted_Manuscript 


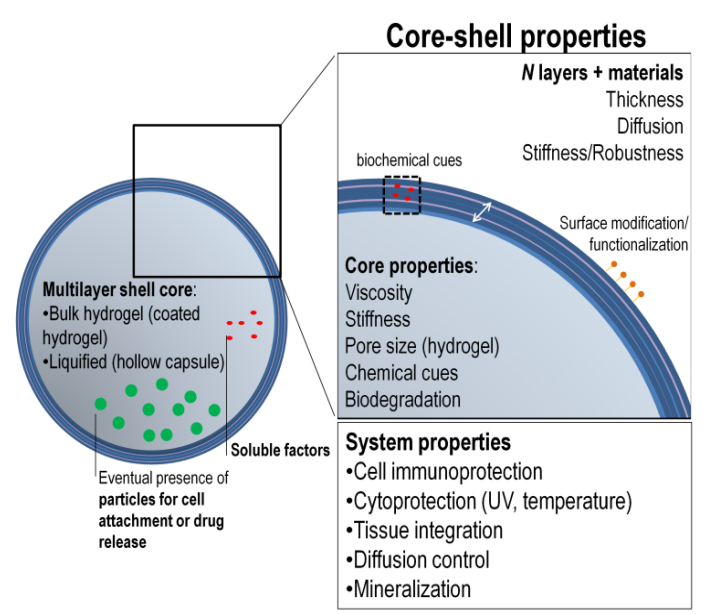

Figure 2. Representation of multilayer coated structures that may have a solid or liquefied core. Inside the structure's core, several assets may be added to promote cellular targeted cell responses. These include solid cell-adhesive microparticles or bioactive agents. Also, the core-shell structure properties may be tailored regarding the core properties and multilayer characteristics, whose outer part may be later modified or functionalized. These systems find application in a wide range of biomedical and biotechnological fields.

\section{Development of LbL cell encapsulation systems: a requirement-based approach contemplating biomedical applications}

The design of LbL coatings targeting cell encapsulation should take into account a critical and careful analysis of materials' requirements/specific applications relationships. Some crucial features of LbL systems for cell encapsulation in different application fields will be discussed in this section.

\subsection{Cytocompatibility}

The design of a cytocompatible, non-toxic and non-immunogenic coating is vital to avoid unwanted cell death and inflammatory response during LbL cell encapsulation. Polymer toxicity in LbL structures may be attributed to cellular internalization of LbL particles, contact of materials with cell membrane, or leaching of toxic compounds from used materials ${ }^{[62]}$. Due to their frequent use for direct electrostatic LbL cell coating, polycations biocompatibility must be discussed. It often depends on the polycations' (i) molecular weight ${ }^{[63]}$, (ii) charge density ${ }^{[18]}$, (iii) structure and sequence (block, random, linear, branched) and (iv) conformational flexibility. Changes in the molecular weight of $P L{ }^{[64]}$ and $P E{ }^{[65]}$ resulted in a different biocompatibility degree of the polymers. Higher charge density, resulting from the number and the three-dimensional arrangement of the cationic residues, and highly flexible polymers are more cytotoxic than lower charge density counterparts ${ }^{[62]}$ because $3 \mathrm{D}$ arrangement of cationic charges within the macromolecule determines the accessibility of the charges to the cell membrane ${ }^{[66]}$. Therefore, branched polyelectrolyte polymers are more efficient than linear or globular structures in neutralizing the surface charge of cell membrane. Both natural origin and synthetic materials were used as a cytocompatible material for LbL cell coating strategies Alginate ${ }^{[27]}$ chitosan ${ }^{[27]}$ gelatin ${ }^{[20]}$ hyaluronic acid $^{[25 a]}$, poly(ethylene glycol) ${ }^{[51]}$, poly-L-lysine ${ }^{26 a, 51]}$, poly-diallyldimethyl ammonium chloride ${ }^{[31]}$, poly-styrene sulfonate ${ }^{[31]}$ and extracellular components such as fibronectin ${ }^{[20]}$ are among the cytocompatible
A

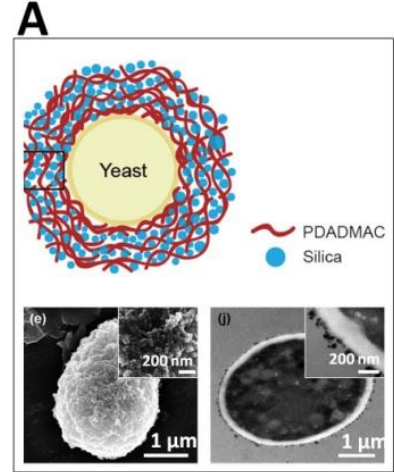

D

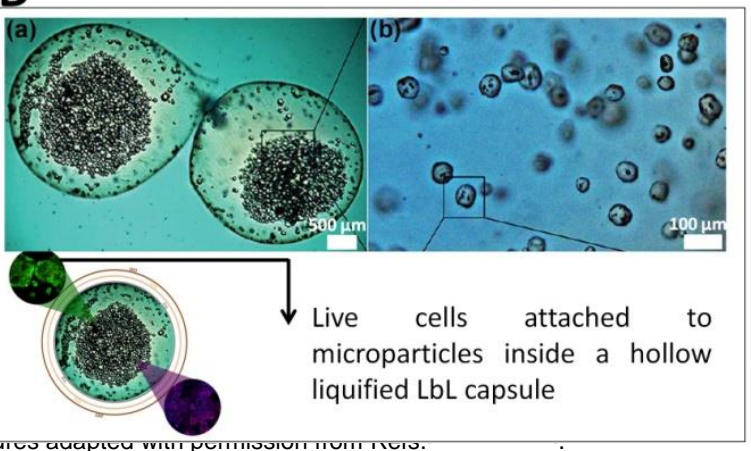

B

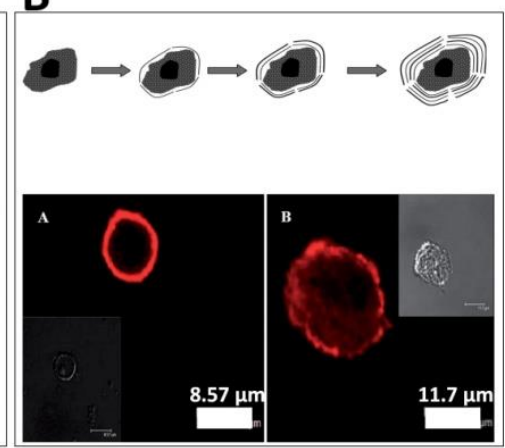

E

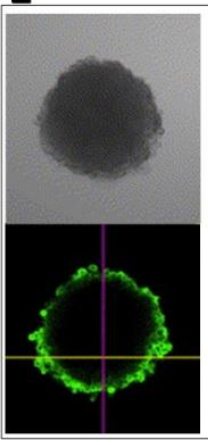

C

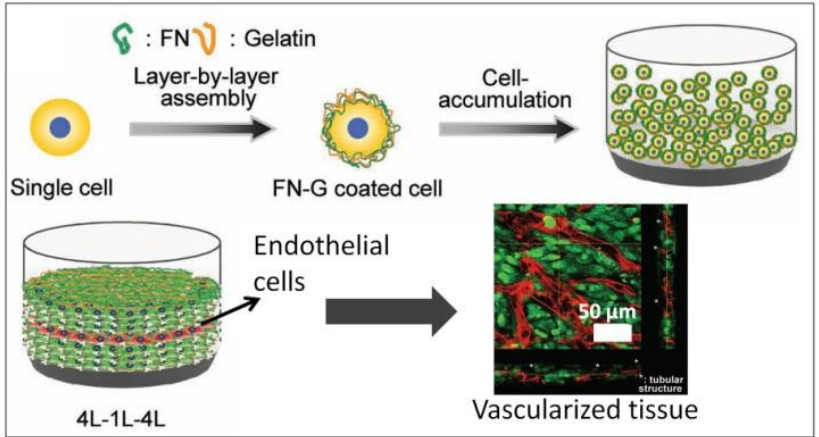

$4 L-1 L-4 L$

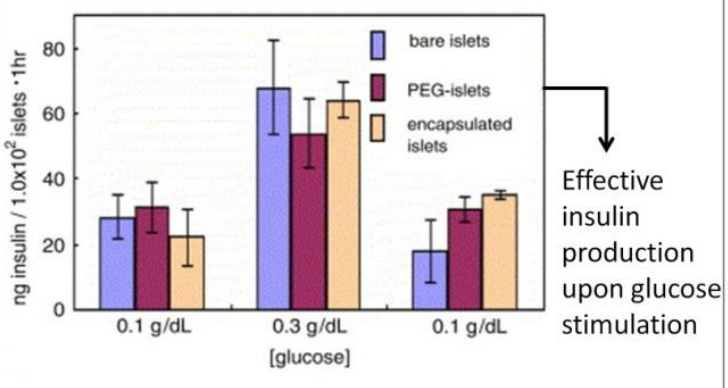

For internal use, please do not delete. Submitted_Manuscript 
materials used for LbL cell encapsulation. Besides biomaterials' cytocompatibility, their degradation products must also not elicit any toxicity or immunogenic undesired response.

\subsection{Robustness}

The concept of adequate robustness associated to living organisms encapsulated in LbL assembled nanostructures is highly dependent on the physicochemical properties of the coatings and the final application desired for the cells/biomaterial system. The most obvious requirements regarding the robustness of LbL directly-coated individual cells or cell aggregates are associated with their manipulation and ability to keep their integrity after implantation. The ability of LbL coated-cells to withstand shear stress is of high importance, as it offers several advantages such as (1) in vitro culture of encapsulated cells in rotational bioreactors, often applied in the biotechnology industry, (2) easy handling of LbL coated cells before implantation and (3) the compatibility with shear stress generated in the implantation environment in vivo. The ability of the constructs to withstand compressive forces, which may be important upon implantation, may be tailored by the adequate selection of biomaterials or by performing post-surface modifications (e.g. crosslinking of materials) to obtain robust coatings.

There is a wider range of requirements for the design of indirectlycoated biological systems, as compared to the design of their directly-coated counterparts. Besides sharing the same concerns related to resistance to shear and compressive stresses, indirectly-coated biological systems must also present adequate resistance to hydrostatic and osmotic pressure. This additional feature is required while delivering the constructs to defect sites using syringes, and for the maintenance of their integrity during implantation time.

The versatility of the LbL technique allows tailoring the adequate strength, viscoelasticity and flexibility of the nanostructured films surrounding the encapsulated cells. The assembled LbL multilayers' stiffness and strength were proved to increase with higher number of deposited layers, molecular weight of the materials and their posterior physical or chemical crosslinking ${ }^{[67]}$.

\subsection{Permeability}

Biomaterials used to encapsulate living cells must act as a semipermeable membrane allowing the passive or active diffusion of vital substances or compounds. To allow high cell viability, the membranes must allow for the passage of gases, permitting the entrance of oxygen to be consumed by the cells, as well as its exchange with $\mathrm{CO}_{2}$ to the exterior part of the cell/biomaterial construct. The cutoff of the membranes must also permit the entrance of glucose and, simultaneously, the removal of cellular metabolites. Diffusion limitation of hydrogel microcapsules was one of the primary reasons for the use of $\mathrm{LbL}$ coatings for islet cell encapsulation ${ }^{[68]}$. Indeed, the smaller thickness of LbL coatings allows a high diffusion rate of glucose and, consequently, a fast response of islet cells to the small changes in the glucose leve[ ${ }^{[50,68]}$ (Figure 3E). The application of nanocoated cells or cell aggregates for allogenic or xenogenic transplantation showcases the importance of building encapsulation systems with adequate semipermeable properties.
In this case, the materials used for cellular encapsulation must impair the entrance of immune system cells, as well as antigen presenting molecules, while still permitting the efficient diffusion of oxygen, nutrients and metabolites.

The permeability of LbL nanostructures may be tailored by controlling the molecular weight of the paired molecules, their type of interaction (e.g. ionic, covalent, etc.), the number of reactive groups per molecule and the number of layers deposited. Moreover, the permeability and structure of the nanofilms may be controlled by degradation phenomena. Two-dimensional films showing a modulated release of embedded factors through their degradation by cellular enzymes were designed for wound dressings ${ }^{[69]}$. The application of this concept in cellular coatings may be interesting to modulate the coatings' permeability with time. Bioactive agents may also be uptaken/stored in the LbL coatings in order to induce a time scheduled cascade of biological activities by controlling the degradation rate of the LbL layers ${ }^{[70]}$.

\subsection{Drug uptake and release}

LbL multilayered systems were proven to be suitable for bioactive molecules delivery. Although this approach has been explored for 2D membranes ${ }^{[71]}$ and hollow reservoirs ${ }^{[72]}$, the inclusion of bioactive molecules in LbL coating for the direct or indirect coating of cellular systems is still poorly explored. One approach is related with the control of immune rejection of transplanted patients by the incorporation of bioactive agents and functionalization of $\mathrm{LbL}$ coatings. As an example, LbL coatings of Langerhans islets incorporating anti-Fas antibodies was used to induce $T$ cell apoptotic pathway ${ }^{[73]}$. Moreover, also anti-thrombomodulin agents, heparin and anti-inflammatory agents as alpha1antitrypsine were incorporated in the LbL systems upon islet transplantation ${ }^{[74]}$.

The incorporation of bioactive agents in LbL cell encapsulation system may be useful for (1) the delivery of these agents to the inner part of the system, i.e. to the encapsulated cells (e.g. to control cell function and phenotype such as stem cell differentiation) and (2) to dictate the fate of cells outside the implant (e.g. to control inflammatory response), acting as cell instructive platforms, similarly to the work of Oliveira et al., where LbL films were assembled using platelet lysates to control the behavior of human adipose-derived stem cells in vitro ${ }^{[75]}$.

\subsection{Vascularization}

The majority of human tissues contain a vascularized network that allows the exchange of oxygen/carbon dioxide and nutrients/toxic materials from tissues into the blood stream. Consequently, effective tissue regeneration is often considered dependent on the presence of endothelial cells in order to form blood vessels, as in the absence of such structures cellular viability is often compromised due to hypoxia and cell starvation phenomena. The vascularization of a tissue built by the cell accumulation technique - where single cells are LbL-coated and then accumulated in a 3D configuration - was obtained in a week of incubation by precisely positioning coated endothelial cells in the middle of layers of fibroblasts ${ }^{[28]}$ (Figure $3 \mathrm{C}$ ). Moreover, endothelial cells play important roles in cell-cell crosstalk phenomena, including the induction of osteogenesis of mesenchymal stem cells (MSCs) 
through the production of BMP- $2^{[76]}$. The direct contact co-culture of adipose-derived stem cells with endothelial cells was suggested in hollow capsules containing adhesion particles. The osteogenesis of stem cells was triggered even in basal culture conditions by the crosstalk phenomena with endothelial cells ${ }^{[7]}$. This strategy used for bone regeneration, though, would be invalid for strategies aiming at pancreatic cells transplantation. The pancreatic Langerhans islets correct functioning is maintained by a vascular network setup where the blood vessels remain in the outside part of the islets, separated by a basement membrane that impairs the penetration of the vascular network into the islets ${ }^{[78]}$. In this case, the promotion of ex vivo vascularization in the outer part of the islets before implantation would be desirable.

\subsection{Mineralization}

The deposition of mineralized matrixes on cell surface has been achieved by promoting the deposition of inorganic materials in previously deposited organic multilayers around the cells. These approaches have been suggested as a way to protect cells from external stresses and to design thermotolerant vaccines ${ }^{[37]}$.

Two-dimensional multilayer membranes mineralized during LbL material deposition were suggested for the production of conformal enzyme-loaded layers, with possible application in the synthesis of biofuel cells and sensors ${ }^{[79]}$. The biomimetic mineralization of chitosan/chondroitin sulfate films using calcium and phosphate ions sequential deposition was suggested for bone regeneration ${ }^{[80]}$. The application of a mineralized nanocoating directly on cells has been suggested by Akashi and co-workers, using bilayers of fibronectin and gelatin to coat animal cells, followed by the sequential deposition of calcium chloride and sodium phosphate ${ }^{[81]}$, resulting in the deposition of calcium phosphate in the film. Choi and co-workers reported the LbL nanocoating of Saccharomyces cerevisiae yeasts in highly uniform double layers (with $100 \mathrm{~nm}$ thickness) composed of poly(norepinephrine) and inorganic silica for cytoprotection (including from a lytic enzyme, desiccation, and UV-C irradiation) and control of cells' metabolic activity[37]. Proteomic analysis showed that the encapsulated cells were not harmed during encapsulation, and instead, their response to applied stresses was improved ${ }^{[37]}$. Later on, LbL technique was used to control the thickness of such silica shells in order to encapsulate individual yeasts using a similar bioinspired silification process $^{\left[{ }^{[2]}\right.}$ (Figure $3 A)$.

\subsection{Self-healing and adhesiveness}

Self-healing materials show the ability to autonomously repair in situ in response to damage that may arise from physical and chemical stresses within its use environment ${ }^{[83]}$. They were first suggested as a way to decrease the effects of wear in implantable materials to improve biomaterials lifetime. Achieving materials for cell encapsulation with these characteristics would be relevant for (1) direct coatings, where the possible exposure of allogenic or xenogenic encapsulated biological materials would be avoided by the maintenance of the shell integrity even after occasional disruption and (2) indirect coatings, especially after injection procedures or exposure to high shear stresses, hydrostatic and osmotic pressures, as they would allow the material to recover from microscopic level failures, avoiding macroscopic disruptions and bursting. Another interesting application for self-healing or sticking nanomodified systems would be the induced aggregation of LbL-coated building blocks in vivo or ex vivo.

Most polyelectrolyte multilayer systems with self-healing properties are composed by weak-weak and weak-strong polyelectrolyte interactions. For example, weak polyelectrolyte multilayers of poly(ethylenimine)/PAA (BPEI/PAA) showed selfhealing and adhesive properties, that allowed their use as foldable devices to construct, for example, tubular structures ${ }^{[84]}$. The selfhealing behavior of the multilayers is based on water-induced mobility of polymer chains ${ }^{[85]}$ : in wet conditions the swollen state surface allows defects to be eliminated by rearrangement of polymer chains. In the BPEI/PAA films, the self-healing transition was dependent on the transition of contact between organic solvents and hydration with water ${ }^{[84]}$. Other work reported the preparation of self-healing multilayer structures using non-toxic chitosan and polyacrylic acid. For this system, the self-healing behavior was equally dependent on an external stimuli: the acidification of chitosan to $\mathrm{pH} 3^{[86]}$. These works allow envisioning possible applications of self-healing polyelectrolyte multilayered structures for cell encapsulation. However, stimuli-free or systems dependent on cytocompatible stimuli must be designed in order to achieve an efficient application of these systems. For example, systems based on Diels-Alder reaction (with decreased reaction times, as in this work the reaction took about 7 hours to occur), as the one used to develop a dextran-based self-healing hydrogel under physiological conditions could potentially be applied to LbL strategies ${ }^{[87]}$.

\subsection{Stimuli responsiveness}

Stimuli responsive/smart biomaterials show large conformational changes in response to small environmental stimuli. The stimuli applied to the materials may be of several natures, including temperature, ionic strength, $\mathrm{pH}$ or light ${ }^{[88]}$. Usual re-configurations of such materials usually show a reversible character and include polymer precipitation or gelation, collapse of hydrogel or grafted polymers on surfaces, hydrophobic/hydrophilic transitions and reversible adsorption phenomena ${ }^{[8]}$. Stimuli-responsive biomaterials have been used in fields like bioseparation, drug delivery, reusable enzymatic catalysts, molecular switches, biosensors, regulated protein folding, microfluidics, and gene therapy ${ }^{[89]}$. Polyelectrolyte multilayers have shown $\mathrm{pH}$ and ionic strength sensitivity ${ }^{[90]}$ and several systems have been adapted to respond to temperature ${ }^{[91]}$ or light exposure (a systematic review on light-responsive multilayers can be found $\mathrm{in}^{[92]}$ ). Stimuliresponsive multilayer films and capsules have been suggested for drug delivery applications ${ }^{[60,91,93]}$.

The long term preservation of the LbL coating is desirable for applications involving immunoprotection. However, for autologous approaches in tissue regeneration, an inverse trend is desired. In this scenario, the protective coating of the cells/biomaterials must be degraded as a sequence of response to physiological or external stimuli, after the complete healing of the tissue. Stimuli-responsive LbL films may be interesting for cell coating as they may show on-demand rapid degradation. The coating of cells with polymers that may allow applying reversibly 
different stimuli in the cell membrane as stiffness, surface charge or wettability could also have application for controlled induction of cell responses.

\section{Summary and Perspective}

In this Focus Review, we summarized the applications of multilayer nanocoatings as systems for cellular encapsulation; their application both for nano-functionalization of individual cells' and cell aggregates' surfaces, as well as for the coating of cytocompatible cell-laden materials was contemplated. LbL multilayers are versatile systems that have a high potential to overcome the limitations of the use of bulk hydrogels in applications such as immunoprotection of allo- or xenogenic transplanted cells, or implantation of complex tissue engineered constructs. Moreover, they have also been applied in microbiological approaches aiming at the cytoprotection of living organisms such as bacteria and yeasts. The LbL technique allows a high degree of versatility regarding the final coatings properties. This leaves a wide range of options to explore regarding new structural and multi-functional materials used for each application, LbL buildup properties (e.g. number of layers, time of deposition of each layer) and methods for the deposition of the multilayers. In this context, the further exploitation of microfluidics may play an important role in the future upscaling of highly reproducible nanocoated cellular systems.
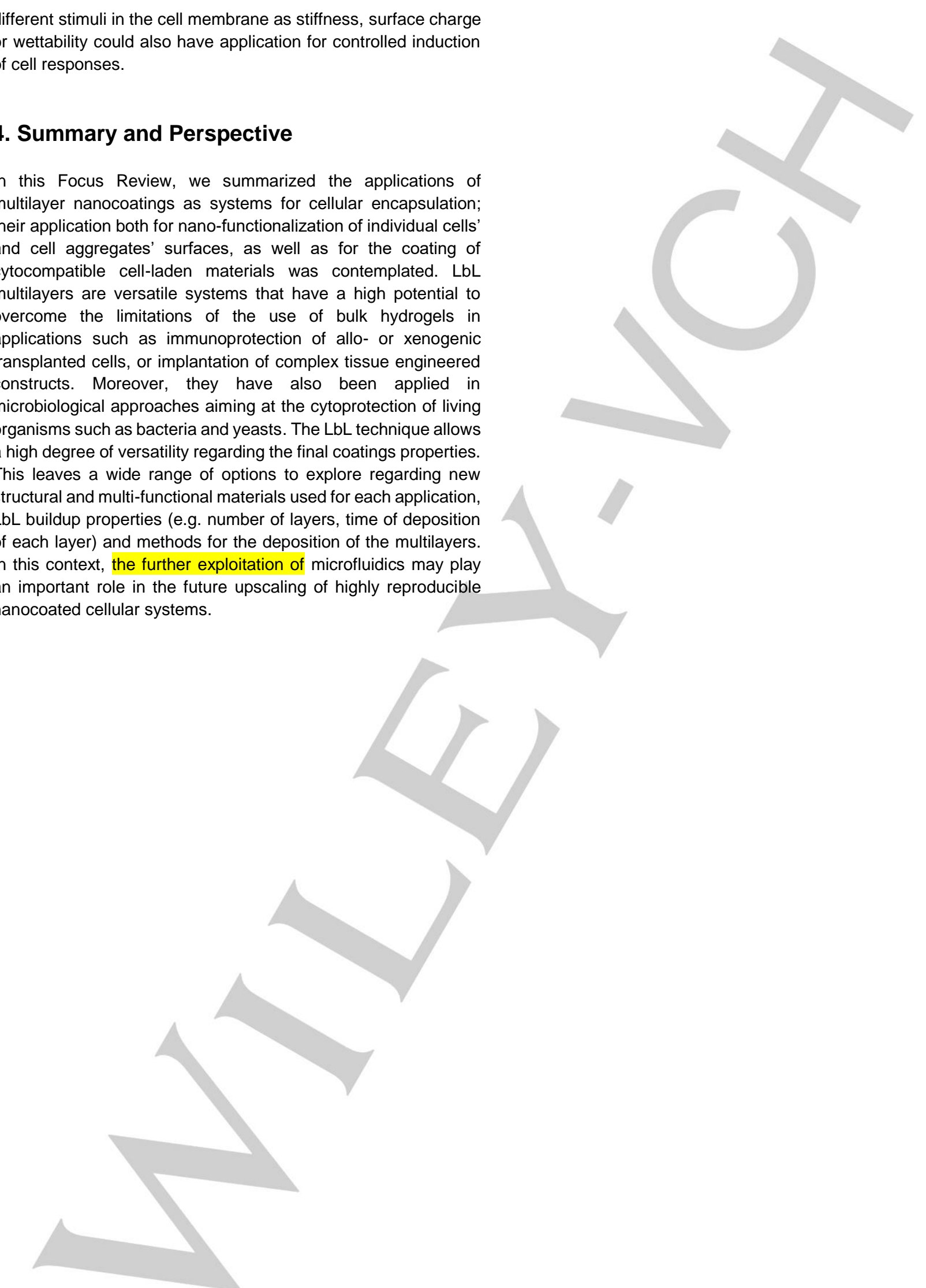

For internal use, please do not delete. Submitted_Manuscript 
WILEY-VCH

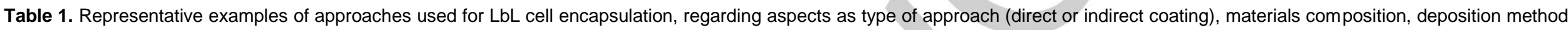
and application.

\begin{tabular}{|c|c|c|c|c|c|c|c|}
\hline \multicolumn{2}{|l|}{ Material } & \multirow{2}{*}{ Cell type } & \multirow{2}{*}{ Objective/outcome } & \multirow{2}{*}{ Comment } & \multirow{2}{*}{$\begin{array}{l}\text { Type of } \\
\text { coating }\end{array}$} & \multirow{2}{*}{ Method } & \multirow{2}{*}{ Ref. } \\
\hline Cation $(+)$ & Anion(-) & & & & & & \\
\hline - & $\begin{array}{l}\text { Fibronectin- } \\
\text { Gelatin }\end{array}$ & $\begin{array}{l}\text { Human dermal } \\
\text { fibroblast cells and endothelial } \\
\text { cells }\end{array}$ & $\begin{array}{l}\text { Formation of a } 3 \mathrm{D} \text { vascularized tissue and human skin } \\
\text { equivalent }\end{array}$ & $\begin{array}{l}\text { LbL performed by interactions through the } \\
\text { collagen-binding domain of fibronectin }\end{array}$ & direct & Dip-coating & {$[28,43]$} \\
\hline $\begin{array}{l}\text { Chitosan } \\
\text { poly(L-lysine) }\end{array}$ & Alginate & $\begin{array}{lr}\text { Immortalized } & \text { mouse lung } \\
\text { fibroblast cell line (L929) }\end{array}$ & Encapsulation of anchorage-dependent cells & Poly(L-lactic acid) used as cell adhesive particles & indirect & Dip-coating & [58a] \\
\hline Chitosan & Alginate & L929 cells & $\begin{array}{l}\text { Preparation of 3D constructs for tissue engineering and organ } \\
\text { printing }\end{array}$ & $\begin{array}{l}\text { 3D spiral construct of cells+alginate obtained by } \\
\text { liquefication of the core alginate }\end{array}$ & indirect & Perfusion & [7a] \\
\hline poly(L-lysine) & $\begin{array}{l}\text { hyaluronic } \\
\text { acid }(\mathrm{HA})\end{array}$ & Mouse mesenchymal stem cells & Maintenance of cell viability \& morphology ( 1 week) & & direct & Dip-coating & [26a] \\
\hline Gelatin & Alginate & Rat Neural Stem Cells (NSC) & $\begin{array}{l}\text { Viability, proliferation, and differentiation of NSCs were not } \\
\text { significantly influenced by the LbL }\end{array}$ & $\begin{array}{l}\text { IGF-1 loaded to the LbL coating enhanced NSC } \\
\text { proliferation }\end{array}$ & direct & Dip-coating & [26b] \\
\hline $\begin{array}{l}\text { poly(L-lysine)-graft- } \\
\text { poly(ethylene glycol) }\end{array}$ & Alginate & Murine pancreatic islets & Cytocompatible encapsulation of cells & & direct & Dip-coating & [30] \\
\hline 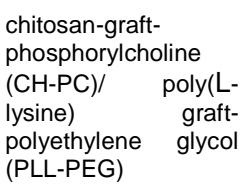 & Alginate & Red Blood Cell & Immunocamouflage of blood group antigens & $\begin{array}{l}4 \text { bilayer-CH-PC/Alginate followed by } 2 \text { bilayer of } \\
\text { PLL-PG/Alginate }\end{array}$ & direct & Dip-coating & [27] \\
\hline
\end{tabular}

For internal use, please do not delete. Submitted_Manuscript 


\begin{tabular}{|c|c|c|c|c|c|c|}
\hline $\begin{array}{l}\text { poly(L-lysine)-graft- } \\
\text { poly(ethylene glycol) } \\
\text { (PLL-g-PEG) }\end{array}$ & Alginate & Murine pancreatic islets & $\begin{array}{l}\text { Automated filtration and washing strategy for islet cell } \\
\text { encapsulation }\end{array}$ & & direct & Dip-coating \\
\hline $\begin{array}{l}\text { poly(N-vinylpyrrolidone) } \\
\text { tannic acid }\end{array}$ & (PVPON)- & $\begin{array}{l}\text { Saccharomyces cerevisiae yeast } \\
\text { cells }\end{array}$ & Maintenance of encapsulated cells' viability and growth & $\begin{array}{l}\text { Hydrogen bonding; higher cell viability compared } \\
\text { to its electrostatic multilayer counterpart }\end{array}$ & direct & Dip-coating \\
\hline
\end{tabular}

For internal use, please do not delete. Submitted_Manuscript 


\section{Acknowledgements}

This paper was financed by the ELASTISLET H2020-NMP-2014646075 project. MB Oliveira acknowledge the Portuguese Fundação para a Ciência e a Tecnologia (FCT) (SFRH/BPD/111354/2015) for the post-doctoral grants, respectively.

Keywords: layer-by-layer, cell encapsulation, nanocoatings, cell nanomodification, hollow capsules

[1] S. G. Zhang, Nat Biotechnol 2003, 21, 1171

[2] a) R. E. McMahon, L. N. Wang, R. Skoracki, A. B. Mathur, J Biomed Mater Res B 2013, 101B, 387; b) J. Kopecek, J. Y. Yang, Angew Chem Int Edit 2012, 51, 7396.

[3] G. Decher, J. D. Hong, Makromol Chem-M Symp 1991, 46, 321.

[4] a) J. Borges, J. F. Mano, Chem Rev 2014, 114, 8883; b) B. Schoeler, S. Sharpe, T. A. Hatton, F. Caruso, Langmuir 2004, 20, 2730; c) B. Jean, L. Heux, F. Dubreuil, G. Chambat, F. Cousin, Langmuir 2009, 25, 3920.

[5] J. J. Richardson, M. Bjornmalm, F. Caruso, Science 2015, 348, 411.

[6] R. R. Costa, J. F. Mano, Chem Soc Rev 2014, 43, 3453.

[7] a) P. Sher, C. R. Correia, R. R. Costa, J. F. Mano, Rsc Adv 2015, 5 , 2511; b) J. M. Silva, A. R. C. Duarte, C. A. Custodio, P. Sher, A. I. Neto, A. C. M. Pinho, J. Fonseca, R. L. Reis, J. F. Mano, Adv Healthc Mater 2014, 3, 433; c) G. B. Sukhorukov, E. Donath, H. Lichtenfeld, E. Knippel, M. Knippel, A. Budde, H. Mohwald, Colloid Surface A 1998, 137, 253; d) F. Caruso, R. A. Caruso, H. Mohwald, Science 1998, 282, 1111.

[8] F. Lim, A. M. Sun, Science 1980, 210, 908.

[9] L. Gasperini, J. F. Mano, R. L. Reis, J R Soc Interface 2014, 11.

[10] a) B. V. Slaughter, S. S. Khurshid, O. Z. Fisher, A. Khademhosseini, N. A. Peppas, Adv Mater 2009, 21, 3307; b) L. Yu, J. D. Ding, Chem Soc Rev 2008, 37, 1473.

[11] S. N. Jayasinghe, Analyst 2011, 136, 878-890

[12] Y. Choo, C.J. Johnson, P. K. Odenwälder, S.N. Jayasinghe. "Nested cell encapsulation", WO2011047870 A1, priority date: 22 Out 2009.

[13] S N. Jayasinghe, J. Auguste, C. J. Scotton, Advanced Materials 2015 , 27, 7794-7799.

[14] V. L. Workman, L. B. Tezera, P. T. Elkington, S. N. Jayasinghe, Advanced Functional Materials 2014, 24, 2648-2657.

[15] B. Al Shammari, T. Shiomi, L. Tezera, M. K. Bielecka, V. Workman, T. Sathyamoorthy, F. Mauri, S. N. Jayasinghe, B. D. Robertson, J. D'Armiento, J. S. Friedland, P. T. Elkington, Journal of Infectious Diseases 2015, 212, 463-473.

[16] a) R. F. Fakhrullin, A. I. Zamaleeva, R. T. Minullina, S. A. Konnova, V. N. Paunov, Chem Soc Rev 2012, 41, 4189; b) Z. L. Zhi, F. Khan, J. C. Pickup, Diabetes Res Clin Pract 2013, 100, 162.

[17] K. Kadowaki, M. Matsusaki, M. Akashi, Langmuir 2010, 26, 5670.

[18] J. S. Martinez, T. C. Keller, 3rd, J. B. Schlenoff, Biomacromolecules 2011, 12, 4063.

[19] H. Zhang, H. Chang, L. M. Wang, K. F. Ren, M. C. Martins, M. A. Barbosa, J. Ji, Biomacromolecules 2015, 16, 3584

[20] M. Matsusaki, K. Kadowaki, Y. Nakahara, M. Akashi, Angew Chem Int Ed Engl 2007, 46, 4689.

[21] H. Ai, M. Fang, S. A. Jones, Y. M. Lvov, Biomacromolecules 2002, 3, 560 .

[22] a) S. Krol, M. Nolte, A. Diaspro, D. Mazza, R. Magrassi, A. Gliozzi, A. Fery, Langmuir 2005, 21, 705; b) R. F. Fakhrullin, J. García-Alonso, V N. Paunov, Soft Matter 2010, 6, 391.

[23] B. Franz, S. S. Balkundi, C. Dahl, Y. M. Lvov, A. Prange, Macromol Biosci 2010, 10, 164
[24] S. Krol, O. Cavalleri, P. Ramoino, A. Gliozzi, A. Diaspro, J Microsc 2003 212, 239.

[25] S. S. Balkundi, N. G. Veerabadran, D. M. Eby, G. R. Johnson, Y. M. Lvov, Langmuir 2009, 25, 14011.

[26] a) N. G. Veerabadran, P. L. Goli, S. S. Stewart-Clark, Y. M. Lvov, D. K. Mills, Macromol Biosci 2007, 7, 877; b) W. Li, T. Guan, X. Zhang, Z Wang, M. Wang, W. Zhong, H. Feng, M. Xing, J. Kong, ACS Appl Mater Interfaces 2015, 7, 3018 .

[27] S. Mansouri, Y. Merhi, F. M. Winnik, M. Tabrizian, Biomacromolecules 2011, 12, 585

[28] A. Nishiguchi, H. Yoshida, M. Matsusaki, M. Akashi, Adv Mater 2011, 23, 3506 .

[29] a) R. F. Fakhrullin, Y. M. Lvov, Acs Nano 2012, 6, 4557-4564. b) E. A. Naumenko, M. R. Dzamukova, G. I. Fakhrullina, F. S. Akhatova, R. F. Fakhrullin, Current Opinion in Pharmacology 2014, 18, 84-90.

[30] J. T. Wilson, W. Cui, V. Kozlovskaya, E. Kharlampieva, D. Pan, Z. Qu, V. R. Krishnamurthy, J. Mets, V. Kumar, J. Wen, Y. Song, V. V. Tsukruk, E. L. Chaikof, J Am Chem Soc 2011, 133, 7054.

[31] M. Germain, P. Balaguer, J. C. Nicolas, F. Lopez, J. P. Esteve, G. B. Sukhorukov, M. Winterhalter, H. Richard-Foy, D. Fournier, Biosens Bioelectron 2006, 21, 1566.

[32] J. H. Park, S. H. Yang, J. Lee, E. H. Ko, D. Hong, I. S. Choi, Adv Mater 2014, 26, 2001.

[33] G. I. Dawlatsina, R. T. Minullina, R. F. Fakhrullin, Nanoscale 2013, 5, 11761-11769.

[34] J. Lee, S. H. Yang, S. P. Hong, D. Hong, H. Lee, H. Y. Lee, Y. G. Kim, I. S. Choi, Macromol Rapid Comm 2013, 34, 1351

[35] J. Lee, H. Cho, J. Choi, D. Kim, D. Hong, J. H. Park, S. H. Yang, I. S. Choi, Nanoscale 2015, 7, 18918.

[36] S. Pandey, F. Afrin, R. P. Tripathi, G. Gangenahalli, J Nanopart Res 2013, 15, 1.

[37] D. Hong, H. Lee, E. H. Ko, J. Lee, H. Cho, M. Park, S. H. Yang, I. S. Choi, Chem Sci 2015, 6, 203

[38] B. Wang, P. Liu, Z. Liu, H. Pan, X. Xu, R. Tang, Biotechnology and Bioengineering 2014, 111, 386-395.

[39] A. Matsuzawa, M. Matsusaki, M. Akashi, Langmuir 2013, 29, 7362.

[40] A. Haisch, A. Groger, C. Radke, J. Ebmeyer, H. Sudhoff, G. Grasnick, V. Jahnke, G. R. Burmester, M. Sittinger, Biomaterials 2000, 21, 1561

[41] A. Diaspro, D. Silvano, S. Krol, O. Cavalleri, A. Gliozzi, Langmuir 2002, $18,5047$.

[42] M. Matsusaki, K. Fujimoto, Y. Shirakata, S. Hirakawa, K. Hashimoto, M. Akashi, J Biomed Mater Res A 2015, 103, 3386.

[43] R. F. Fakhrullin, M.-L. Brandy, O. J. Cayre, O. D. Velev, V. N. Paunov, Physical Chemistry Chemical Physics 2010, 12, 11912-11922.

[44] V. Kozlovskaya, S. Harbaugh, I. Drachuk, O. Shchepelina, N. KelleyLoughnane, M. Stone, V. V. Tsukruk, Soft Matter 2011, 7, 2364.

[45] M. Chanana, A. Gliozzi, A. Diaspro, I. Chodnevskaja, S. Huewel, V. Moskalenko, K. Ulrichs, H. J. Galla, S. Krol, Nano Letters 2005, 5, 2605.

[46] M. D. Tarn, R. F. Fakhrullin, V. N. Paunov, N. Pamme, Materials Letters 2013, 95, 182-185

[47] P. Soon-Shiong, R. E. Heintz, N. Merideth, Q. X. Yao, Z. Yao, T. Zheng M. Murphy, M. K. Moloney, M. Schmehl, M. Harris, et al., Lancet 1994 343, 950.

[48] J. T. Wilson, W. Cui, E. L. Chaikof, Nano Lett 2008, 8, 1940

[49] J. M. Mets, J. T. Wilson, W. Cui, E. L. Chaikof, Adv Healthc Mater 2013, 2, 266.

[50] S. Miura, Y. Teramura, H. Iwata, Biomaterials 2006, 27, 5828.

[51] J. T. Wilson, V. R. Krishnamurthy, W. Cui, Z. Qu, E. L. Chaikof, J Am Chem Soc 2009, 131, 18228

[52] A. A. Tomei, V. Manzoli, C. A. Fraker, J. Giraldo, D. Velluto, M. Najjar, A. Pileggi, D. Molano, C. Ricordi, C. L. Stabler, J. A. Hubbell, P Natl Acad Sci USA 2014, 111, 10514

[53] a) P. Chen, X. Wang, Y. Dong, X. H. Hu, Int J Polym Sci 2015; b) D. Lynam, C. Peterson, R. Maloney, D. Shahriari, A. Garrison, S. Saleh, S. Mehrotra, C. Chan, J. Sakamoto, Carbohyd Polym 2014, 103, 377.

For internal use, please do not delete. Submitted_Manuscript 
[54] S. Yamanlar, S. Sant, T. Boudou, C. Picart, A. Khademhosseini, Biomaterials 2011, 32, 5590 .

[55] Y. M. Lu, Y. Wu, J. Liang, M. R. Libera, S. A. Sukhishvili, Biomaterials 2015, 45, 64.

[56] W. M. Fritschy, G. H. Wolters, R. van Schilfgaarde, Diabetes 1991, 40, 37.

[57] B. J. Kim, T. Park, S. Y. Park, S. W. Han, H. S. Lee, Y. G. Kim, I. S. Choi, Chem-Asian J 2015, 10, 2130.

[58] a) C. R. Correia, R. L. Reis, J. F. Mano, Biomacromolecules 2013, 14 , 1250; b) N. L. Costa, P. Sher, J. F. Mano, Adv Eng Mater 2011, 13, B218.

[59] a) R. R. Costa, A. Girotti, M. Santos, F. J. Arias, J. F. Mano, J. C. Rodriguez-Cabello, Acta Biomater 2014, 10, 2653; b) P. Sher, C. A. Custodio, J. F. Mano, Small 2010, 6, 2644.

[60] R. R. Costa, E. Castro, F. J. Arias, J. C. Rodriguez-Cabello, J. F. Mano, Biomacromolecules 2013, 14, 2403.

[61] J. Flemke, M. Maywald, V. Sieber, Biomacromolecules 2013, 14, 207.

[62] D. Fischer, Y. Li, B. Ahlemeyer, J. Krieglstein, T. Kissel, Biomaterials 2003, 24, 1121.

[63] C. Brunot, L. Ponsonnet, C. Lagneau, P. Farge, C. Picart, B. Grosgogeat, Biomaterials 2007, 28, 632.

[64] D. M. Morgan, V. L. Larvin, J. D. Pearson, J Cell Sci 1989, 94 ( Pt 3), 553.

[65] D. Fischer, T. Bieber, Y. Li, H. P. Elsasser, T. Kissel, Pharm Res 1999, 16, 1273.

[66] H. J. Ryser, Nature 1967, 215, 934.

[67] J. M. Silva, S. G. Caridade, N. M. Oliveira, R. L. Reis, J. F. Mano, J Mater Chem B 2015, 3, 4555 .

[68] D. W. Scharp, P. Marchetti, Adv Drug Deliv Rev 2014, 67-68, 35

[69] A. Agarwal, T. L. Weis, M. J. Schurr, N. G. Faith, C. J. Czuprynski, J. F. McAnulty, C. J. Murphy, N. L. Abbott, Biomaterials 2010, 31, 680.

[70] J. M. Garza, N. Jessel, G. Ladam, V. Dupray, S. Muller, J. F. Stoltz, P. Schaaf, J. C. Voegel, P. Lavalle, Langmuir 2005, 21, 12372.

[71] a) T. Crouzier, L. Fourel, T. Boudou, C. Albiges-Rizo, C. Picart, Adv Mater 2011, 23, H111; b) S. G. Caridade, C. Monge, J. Almodovar, R. Guillot, J. Lavaud, V. Josserand, J. L. Coll, J. F. Mano, C. Picart, Acta Biomater 2015, 15, 139.

[72] R. R. Costa, M. Alatorre-Meda, J. F. Mano, Biotechnol Adv 2015, 33 , 1310.

[73] P. S. Hume, K. S. Anseth, Biomaterials 2010, 31, 3166.

[74] a) J. T. Wilson, C. A. Haller, Z. Qu, W. Cui, M. K. Urlam, E. L. Chaikof, Acta Biomater 2010, 6, 1895; b) S. Cabric, J. Sanchez, T. Lundgren, A
Foss, M. Felldin, R. Kallen, K. Salmela, A. Tibell, G. Tufveson, R. Larsson, O. Korsgren, B. Nilsson, Diabetes 2007, 56, 2008; c) N. M Luan, Y. Teramura, H. Iwata, Biomaterials 2011, 32, 6487; d) Z. L. Zhi, J. Singh, A. L. F. Austin, D. C. D. Hope, A. J. King, S. J. Persaud, P. M Jones, Chem Commun 2015, 51, 10652.

[75] S. M. Oliveira, V. E. Santo, M. E. Gomes, R. L. Reis, J. E. Mano, Biomaterials 2015, 48, 56 .

[76] M. Grellier, L. Bordenave, J. Amedee, Trends Biotechnol 2009, 27, 562.

[77] C. R. Correia, R. P. Pirraco, M. T. Cerqueira, A. P. Marques, R. L. Reis J. F. Mano, Scientific Reports 2016, accepted.

[78] S. Morini, M. L. Brown, L. Cicalese, G. Elias, S. Carotti, E. Gaudio, C. Rastellini, J Anat 2007, 210, 565

[79] N. R. Haase, S. Shian, K. H. Sandhage, N. Kroger, Adv Funct Mater 2011, 21, 4243

[80] A. J. Leite, P. Sher, J. F. Mano, Mater Lett 2014, 121, 62.

[81] S. Saha, T. Yoshikai, C. Y. Liu, M. Matsusaki, X. B. B. Yang, M. Akashi, Chem Lett 2015, 44, 1714.

[82] H. Lee, D. Hong, J. Y. Choi, J. Y. Kim, S. H. Lee, H. M. Kim, S. H. Yang I. S. Choi, Chem-Asian J 2015, 10, 129.

[83] N. Y. Abu-Thabit, A. S. Hamdy, Surface and Coatings Technology.

[84] Y. Q. Gu, N. S. Zacharia, Adv Funct Mater 2015, 25, 3785

[85] E. V. Skorb, D. V. Andreeva, Polym Int 2015, 64, 713

[86] Y. X. Zhu, H. Y. Xuan, J. Y. Ren, L. Q. Ge, Soft Matter 2015, 11, 8452.

[87] Z. Wei, J. H. Yang, X. J. Du, F. Xu, M. Zrinyi, Y. Osada, F. Li, Y. M. Chen, Macromol Rapid Comm 2013, 34, 1464

[88] J. F. Mano, Adv Eng Mater 2008, 10, 515

[89] M. A. C. Stuart, W. T. S. Huck, J. Genzer, M. Muller, C. Ober, M. Stamm G. B. Sukhorukov, I. Szleifer, V. V. Tsukruk, M. Urban, F. Winnik, S. Zauscher, I. Luzinov, S. Minko, Nat Mater 2010, 9, 101.

[90] J. M. Silva, S. G. Caridade, R. R. Costa, N. M. Alves, T. Groth, C. Picart R. L. Reis, J. F. Mano, Langmuir 2015, 31, 11318

[91] R. R. Costa, C. A. Custodio, F. J. Arias, J. C. Rodriguez-Cabello, J. F. Mano, Small 2011, 7, 2640.

[92] J. Borges, L. C. Rodrigues, R. L. Reis, J. F. Mano, Adv Funct Mater 2014 24, 5624.

[93] W. Xu, P. A. Ledin, F. A. Plamper, C. V. Synatschke, A. H. E. Müller, V. V. Tsukruk, Macromolecules 2014, 47, 7858. 


\section{Entry for the Table of Contents}

\section{FOCUS REVIEW}

Dressed up to be functional: In this Focus Review we discuss the use of nanostructured multilayer coatings for cell encapsulation. Their role in direct cellular surface modification of single cells and cellular aggregates, as well as in the coating of biomaterials for functionalization or design of hollow capsules is discussed. Insights regarding the optimization of such systems are also provided.

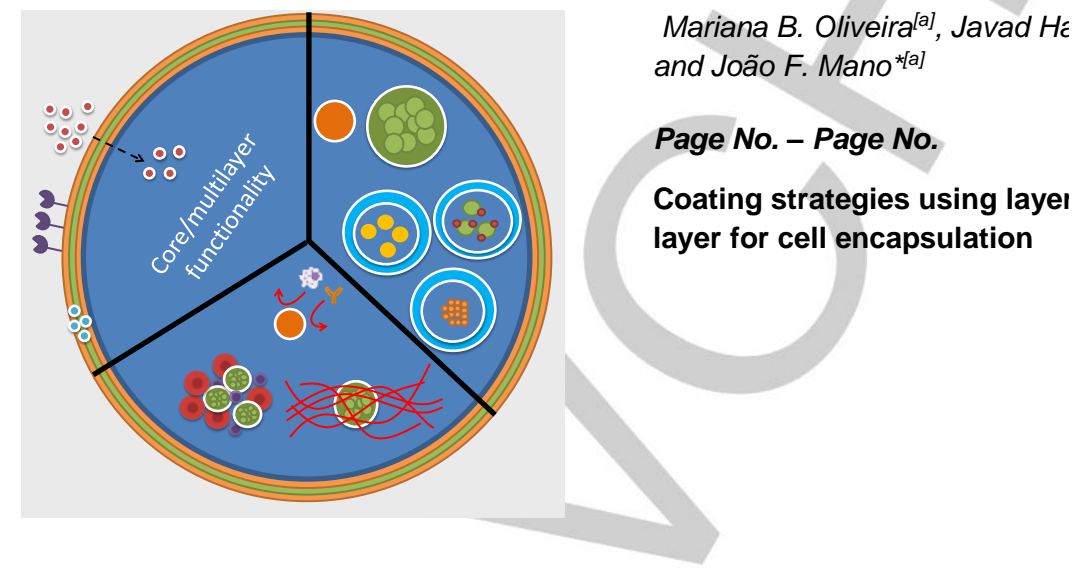

Mariana B. Oliveira ${ }^{[a]}$, Javad $H_{c}$

Coating strategies using layeI layer for cell encapsulation 